\title{
Trends that Shaping Education in Bangladesh
}

\author{
Sevinç Tunali \\ PhD., CO-Founder at PEDUDI Information Technologies Inc., Turkey. \\ Email:sevinctunali@yahoo.com
}

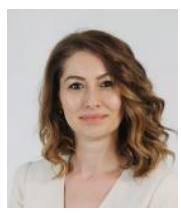

\begin{abstract}
Bangladesh has a highly complicated education system with a wide variety of institutions in both primary and secondary levels. The total number of students in primary and secondary level is higher than 25 million. This huge system need to forecast the future for the sake of all stakeholders' students, parents, teachers alike. This study aims to inquire trends that shaping the future of education in Bangladesh. For this aim trends analysis was used. Trend analysis is a technique to scan drivers of change and supports as a baseline to create new ideas or policymaking for the future. This s a qualitative study therefore, natural observations $(\mathrm{N}=3)$ and interviews $(\mathrm{N}=16)$ are major tools for data gathering. As a result, this study provides information for major trends that shaping the future of primary and secondary schools in Bangladesh. According to the results of the study, there are two main trends. These are (1) Poverty and (2) Knowledgeintensive economy. Poverty theme has three subthemes: (1.1) Population, (1.2) urban poverty and (1.3) child poverty, respectively. Lastly, Skills for the future of work is subtheme of Knowledgeintensive economy.
\end{abstract}

Keywords: Trend analysis, Qualitative study, Schools of the future, Schools in Bangladesh, Poverty, Knowledge-intensive economy, Future of work.

Citation | Sevinç Tunali (2019). Trends that Shaping Education in Bangladesh. Asian Journal of Education and Training, 5(4): 548-554.

History:

Received: 2 August 2019

Revised: 6 September 2019

Accepted: 8 October 2019

Published: 25 November 2019

Licensed: This work is licensed under a Creative Commons

Attribution 3.0 License $(\mathrm{cc})$

Publisher: Asian Online Journal Publishing Group
Funding: This study received no specific financial support.

Competing Interests: The author declares that there are no conflicts of interests regarding the publication of this paper.

Transparency: The author confirms that the manuscript is an honest, accurate, and transparent account of the study was reported; that no vital features of the study have been omitted; and that any discrepancies from the study as planned have been explained.

Ethical: This study follows all ethical practices during writing.

\section{Contents}

1. Introduction

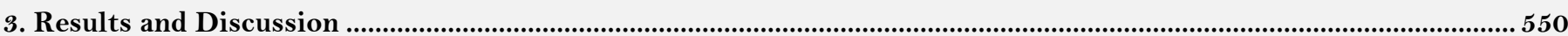

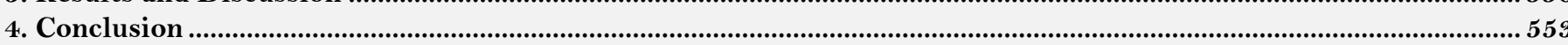

References. 


\section{Contribution of this paper to the literature}

This study contributes to the existing literature by inquiring trends that shaping the future of education in Bangladesh.

\section{Introduction}

European colonization was the most important influencer of the history of South Asia. For many centuries, this region lived under the control of other nations. The power struggle of the Europeans had reigned until WWII. After the war, British India becomes five independent states: India, Pakistan (East and West), Dominion of Ceylon, Union of Burma and Kingdom of Sikkim. In 1971, the Bangladesh War of Independence, East Pakistan had become Peoples Republic of Bangladesh. In light of the above-mentioned very short history of the region can give perspective on the socio-politic structure of Bangladesh. On the one hand, this land newly liberated and strive to develop and on the other hand Bangladeshi want to protect their cultural (language, way of living, customs, etc.) and religious values. In this aggravated circumstances education system is also receiving its share (Chowdhury and Kabir, 2014). The structure of education system in Bangladesh consists of 5 years of primary education (grades 15), 3 years of junior (or lower) secondary education (grades 6-8), 2 years of secondary education (grades 9-10), and 2 years of senior or higher secondary education (grades 11-12). The Ministry of Primary and Mass Education (MOPME) is responsible for primary education, non-formal education, and mass literacy. Meanwhile, the Ministry of Education (MOE) is responsible for secondary education (Asia Development Bank (ADB), 2018). For primary education Bangladesh Bureau of Educational Information and Statistics (Bangladesh Bureau of Educational Information and Statistics, 2018) stated that there are 25 types of schools - including various types of government, community, nongovernment, and nongovernment organization (NGO) schools and religious schools (madrasahs) (ADB, 2018). In terms of the curriculum, schools in Bangladesh divides to two main bodies: General education and Madrasah education. In general education, there are Private schools and Public schools. Most of the private schools' medium of instruction is English (Sommers, 2011; Chowdhury and Kabir, 2014; Rahman et al., 2019). English medium schools are accredited by NEASC, CoIS, IGCSE, Edexcel and CIE, and mostly located in big cities (97,96\% in total 147 schools). In Dhaka number of schools are 131, in Chittagong \#9 and Sylhet \#7 respectively. Total 80,511 students were enrolled to these schools in 2017 (Banbeis, 2018).

Additionally, madrasah education has two main ecole: Aliya madrasahs and Quomi madrasahs. Madrasah education divides to five levels and their gross enrolment rates are: (1) Ebtedayee for 6-10 age students (11.50\%), (2) Dakhil for 11-15 ages students (10.27\%), (3) Alim for 16-17 ages students (3.35\%), (4) Fazil for university level students and (5) Kamil for master's degree students (Banbeis, 2018). In Aliya madrasahs, religious (Qur'an, Hadith and Tafsir) and academic subjects (mathematics, science, social sciences, geography, economy, etc.) study together and there are some English medium madrasahs established as well. There are some public Aliya madrasahs (attached Ebtedayee, total \#9098) but most of them of are private and semi-private (Independent Ebtedayee, Total \#3670/ government supported but privately run) (Banbeis, 2018). On the other hand, Quomi madrasahs (total \#13.902) are privately run institutions and they are not under control of the Ministry of Education in Bangladesh in terms of funds and curriculum. In Bangladesh total 2.453.364 students were enrolled to madrasah education in 2017 (Ali, 2007; Banbeis, 2018). Most of the Quomi (or Quomy) madrasahs' medium of instruction is Arabic and Bengali (recently replaced with Urdu), and main objective of curriculum is Qur'an. There is no accreditation for primary, middle and high school level of Quomi madrasah but university level they have accreditation.

Education system not only related to the organization of institutions but also there is an intimate connection with economic and socio-demographic features of the country. Bangladesh has one of the most density of population in such a small land and many of the people live under extreme poverty. As we all know, education is the most influential tool against poverty but a high proportion of illiterate rates, continuous migration and shortage of teachers making this situation even harder.

\section{Method}

\subsection{Design of the Study}

This research designed as a Trend Analysis. Trend Analysis is a method for studies about the future and qualitative methods (observation and interview) were used to gather data on trends shaping education in Bangladesh. It is often used to project future events by using past or current data. In other words, this technique aims to provide an opinion of how the natural power for shifting has timely progressed and how much its likelihood of occurrence is (Organisation for Economic Co-operation and Development, 2006; Tunalı and Kiraz, 2017a; Mateu et al., 2018; Tunalı, 2019).

This study attempts to provide answer to the following research question: What are the perceptions of experts in terms of trends shaping education in Bangladesh? The results of this question have significance to illuminate the ongoing situation of education in Bangladesh and provide a vision for future opportunities. This trend analysis study also depicts social, political and educational treats and opportunities that may support desirable futures and avoid undesirable. Finally, yet importantly, this study is evidence of long-term policymaking for the future in the field of education in Bangladesh. To provide answers for the research question natural observations were conducted in three different kinds of schools in Dhaka (a public school ( $\mathrm{SCH} 1)$, a semi-private school (SCH2) and a private school $(\mathrm{SCH} 3))$. Variety in observed school types provides valuable information according to different implications in education. There are also many other school types like madrasah and slum schools in Bangladesh but this research is limited with schools in the city center of Dhaka and serves for general education (primary and secondary level) to middle and high socio-economic class children. SCH1 is located in the Dhaka University area and teaches primary and middle school level students. This school follows the standard curriculum provided by the National Curriculum and Textbook Board (NCTB) by double shifting. In the morning shift, the Bangla version and the afternoon shift English version of the curriculum are implementing. $\mathrm{SCH} 2$ is also located in the Dhaka University area. This is a semi-private school that parents are supporting school annually in addition to government funds. This school is implementing the curriculum provided by NCTB too. It has both Bangla and 
English version curriculum classes. SCH3 is a private school that follows the Cambridge University curriculum and the medium of instruction is completely in English.

Finally, interviews were used to reveal the perceptions of experts about trends shaping education in Bangladesh. Interviews were conducted in Dhaka and Istanbul. The researcher started interviews in Istanbul by using snowball-sampling method to reach participants. These participants $(\mathrm{N}=4)$ were Citizens of Bangladesh who temporarily study or work in Istanbul Table 1. Interviews in Dhaka were scheduled with the help of Genocide Studies Center, Dhaka University and this institution provided one Bangladeshi researcher for counseling purposes during interviews and observations. Maximum variation sampling method to reach information-rich people $(\mathrm{N}=12)$ who were knowledgeable both in sociology, education and economics to obtain detailed information and make connections between social context and schools see Table 1. All interviews in Istanbul and Dhaka were conducted in English. Interviewees elaborated on the themes driven from document analysis and further discussed the relevant trends in Bangladesh context. First, the researcher conducted and recorded all interviews. Snowball sampling procedure was used and all participants have $\mathrm{PhD}$. in their area of specialization.

Table-1. Trends interview participants.

\begin{tabular}{|c|c|c|c|c|}
\hline No of participants & Title & Gender & Major & Location of interview \\
\hline INT 1 & Professor & Male & Rector & Dhaka \\
\hline INT 2 & Professor & Female & Curriculum and Instruction (Education) & Dhaka \\
\hline INT4 & Professor & Male & Sociology & Dhaka \\
\hline INT5 & Professor & Female & International Relations & Dhaka \\
\hline INT6 & CEO of a NGO & Female & Education & Dhaka \\
\hline INT9 & School Manager & Female & Education & Dhaka \\
\hline INT10 & School Manager, PhD. & Female & Education & Dhaka \\
\hline INT11 & Consulate, PhD. & Male & International Relations & İstanbul \\
\hline INT12 & Visiting Scholar & Male & Economy & İstanbul \\
\hline INT13 & Visiting Scholar & Male & Economy & İstanbul \\
\hline
\end{tabular}

Semi-structured interviewing method was used to gather data from participants. The Interview Schedule consisted of five fundamental questions which were developed based on the data driven from document review (desk research) (Tunalı and Kiraz, 2017a; Tunalı, 2019). Question (1), "Which trends are relevant to Bangladesh context?" was asked to the interviewees to find out the most relevant trends in Bangladesh. Question (2) was "Are there other trends to take into account?". The researcher derived main trends from the international literature as there can be other local trends to be considered. Question (3) was "Which trends demonstrate critical importance for Bangladesh Education?". All trends are highly important but this trend analysis aimed to determine the most crucial ones. Question (4), "What will the impact of these crucial trends be on Bangladesh education in the future?" was the seminal part of the trends interviews. After that point, the participants gave a massive amount of data related to their previous responses. With Question (5), "How can we deal with these trends in the future? Can we influence or react to them?", the researcher gathered data regarding suggestions by the participants on the mentioned trends shaping education.

\subsection{Data Analysis}

The transcribed interviews were analyzed through content analysis. Content analysis involves conceptualizing data, and then organizing them according to those concepts and determining themes (Bogdan and Biklen, 1992). Analysis procedure for Trend Interviews were basically characterized as an inductive approach (post-defined).

\subsection{Trustworthiness}

According to Shenton (2004) in many studies in which qualitative methods are applied, the researchers choose a specific terminology to stay away from the positivism. These qualitative researchers ought to take into consideration the four criteria that Guba (1981) based on: Credibility, Transferability, Dependability, and Confirmability. In this study, the procedures followed by the researcher were Prolonged Engagement, Persistent Observation, Peer debriefing, Triangulation of data sources (participants from different backgrounds) and methods (document analysis and interviews) for the credibility of this study. Transferability of the study was supported by following a thick description technique to describe the context in detail. To address the dependability, study processes were reported in detail and an inquiry audit procedure was followed. Last but not least, for the sake of confirmability, the peer review process was used. At all stages of the research, the Code for Ethics (American Educational Research Association (AERA), 2011) was followed.

\section{Results and Discussion}

This study aims to provide information for major trends that shaping the future of primary and secondary schools in Bangladesh. According to the results of the study, there are two main trends. These are (1) Poverty and (2) Knowledge-intensive economy.

\subsection{Poverty}

Poverty is one of the oldest enemies of humankind since the beginning of the history. For 200 years, the income gap between developed and developing countries has been widening rapidly. Despite all the progress made 
by middle-income countries, the gap between the richer and poorer regions is not decreasing (OECD, 2016; Tunalı and Kiraz, 2017b). Economic history of Bangladesh started shortly after independence in 1971. For the last decade, economic development is around 7\% per year (INT3). Although this is one of the highest rates in the world according to OECD more than $80 \%$ of the population live with less than $\$ 2$ a day. Bangladesh has great potential but almost $50 \%$ of the population living in Asia/ Pacific countries and economies is poor, and 1/5 is extremely poor (OECD, 2011). Before the independence of Bangladesh India and Pakistan was dominated the economy and all there is no industry in this region. Economy was mostly based on agriculture (jute, rice, cereal, vegetables, and fruit) more than $70 \%$ of the population is directly or indirectly employed in the sector (ADB, 2018).. Last two decades leather, processed fish and textile industries' contributions are higher than other fields.

Poverty has a considerable impact on children's schooling, in terms of enrollment, participation, attendance, and success (Sommers, 2011). Additionally the lack of health condition of children and malnutrition is highly related with poverty and important indicators for academic success as well. World Bank (2011b) cites the depth of this problem: "Chronic malnutrition pervades all socioeconomic strata in Bangladesh, affecting 56 percent of children among the poorest and 32\% among the wealthiest quintiles" (p. 1). According to the studies of Hossain and Zeitlyn (2010) (CREATE's Bangladesh wide school survey (ComSS)) there is a significant relationship between poverty, poor health, lack of school materials and exclusion from education. Pridmore (2007) states that poorer children were more likely to be in the category of children with health problems $(\mathrm{p}<.01)$. In addition to that children with poor health have low achievement and high repetition compared to children with good health ( $<<.01)$ (Pridmore, 2007).

\subsection{Population}

One of the reasons of the population is developments in health sector. Improvements in medicine and medical technologies provide us many ways to survive longer. According to the estimates of the United Nations' (UN) studies, the present population of the world is 6.9 billion and population will become more than 9 billion by 2050 (OECD, 2010; Tunalı and Kiraz, 2017b). Birth rates in OECD countries dropped dramatically after the 1960s. The average number of children per woman was 3.2 until 1960 and this rate declined to 1.7 around the 2000s. Despite this dramatically falling birth rate in other countries, birth rates in Bangladesh are still one of the highest among South Asia (OECD, 2011). Early age marriage is one of the most important indicator for birth rates. One participant highlighted that "Although enrolment rates of boys and girls are equal, dropout rates are turn against to girls. Early age marriage of girls increasing the dropout rates" (INT8). Population is a very important indicator in education because there is a reciprocal relationship between population and education. Education not only shapes dispositions and attitudes underpinning these demographic features but also is shaped by them, especially in terms of the availability and access of resources for educational purposes (OECD, 2010).

\subsection{Urban Poverty}

As a natural result of urbanization, the number of people living in cities is increasing. This trend towards urbanization is happening in both developed and undeveloped countries. Especially in less developed countries, this trend often creates problems like a shortage of infrastructure in the cities. On the other hand, employment and education opportunities are still the main "pull" factors for many who decide to migrate to urban areas. There are also some other local "push" factors that Bangladeshi are exposed in the rural area. Such as, Bangladesh have been exposed to many natural disasters until today. Tornadoes, floods, landslides, riverbank erosion are very common during monsoon rain season that usually damages the lands and residential areas.

Many people migrate to urban areas from rural areas for better living conditions in Bangladesh. Dhaka is one of the most crowded cities in the world that have a total population of around 19 million with a population growth of 4.2\% annually (World Population Review, 2018). Public schools average student to teacher ratio improved 50:1 in 2007 to about 40:1 in 2016 but in some districts of Dhaka, this rate is 1:120. People who live in slums of Dhaka are the people that suffers urban poverty most (Teach for Bangladesh, 2016; ADB, 2018). In secondary level schools average student to teacher ratio in public schools is 1:42 (Banbeis, 2018). The level of poverty has decreased, and household income has increased considerably, during the period 2005-10, in urban as well as rural areas. Urban poverty rates decreased to $21.3 \%$ from 28.4 between 2005 to 2010 (Banbeis, 2018).

\subsection{Child Poverty}

Despite growing affluence in the world, trends in inequality display the widening gap between rich and poor regions. When we go deeper into this data, there is another striking result, child poverty. Children's chances in life depend on the conditions under which they are born and grow up. While it is possible to measure overall poverty in a society, the number of children living in poverty can also be identified. This number considerably varies among OECD countries. Although intergenerational transmission of educational disadvantage has declined in general, the rates in Bangladesh are still rising (OECD, 2011).

Bangladesh's combat against poverty have been continuing in every front. One need to keep in mind before making an inference about education because Bangladesh is a relatively young republic and after independence the huge amount (\%90) of citizens were illiterate (INT3). In the year of independence of Bangladesh (1971) the adult literacy rate was $17.6 \%$ and during the early 1990 s, only $35 \%$ of the country's adult population was literate (BBS, 1981 as stated in Ahmad (2007); ADB (2008). For this reason, improving rates of schooling have been given priority in the past. Nowadays, people have great expectations from schools when compared with a century ago. People are also aware of not quantity but quality (INT3). For this reason, focusing on school empowerment can be very helpful to break the vicious cycle of poverty and low quality education. One of the interviewees who spent more than four decades teaching at different universities in Bangladesh stated that Quality of education decreasing every day. As a result, number of Coaching centers and private tutoring increased. These institutions become more important than regular schools. Effect of rote learning its effects also higher education. There are not familiar with reasoning they just memorize (INT8). Sommers (2011) also mentioned her report for perception among parents that children at government schools and community schools must attend private tutoring in order to learn well (p.22) (Nath, 2007). claims that nearly $38 \%$ of primary-aged students pay for private tutoring, with percentages climbing from roughly 
$25 \%$ of students in $1^{\text {st }}$ grade to over $50 \%$ of students in $5^{\text {th }}$ grade with boys much more likely to receive this support than girls (44\% versus 31\%) (p.28). The competitive structure of the education system is the reason for coaching centers. The data according to Banbeis (2018) indicated that for Ebtedayee Education Completion Examination (EECE) between 2010 and 2016, pass rates were increased from 82.01\% to 96.08\%. Primary Education Completion Examination (PECE) between 2010 and 2016, pass rates were also increased from 88.84 to 98.51 (Amin and Greenwood, 2018). However, participants stated that quality of these exams are questionable (INT1, INT2, INT12, INT3, INT14, and INT15). Global Education Monitoring Report (2017) stated that lack of capacity to monitor centers in Bangladesh, for example, has undermined government attempts to cap tutoring.

This opinion is highly remarkable because on the one hand, data from BANBEIS claim that every year more student be successful in national student assessments on the other hand according to the national student assessments', students' performance has declined since 2011 . In 2015, only 65\% and 41\% of grade 3 students performed at their levels or above on Bangla and mathematics, down from $68 \%$ and $50 \%$ in 2011 , and $75 \%$ and $57 \%$ in 2013. The performance is even lower for grade 5. Only $23 \%$ and $10 \%$ of grade 5 students performed at their levels on Bangla and mathematics in 2015, down from 25\% and 32\% in 2011, and 25\% in 2013 (ADB, 2018).

Moreover, nearly all public schools are running double shifts and the teacher-student interaction time is almost 50\% lower than the international standard of hours (900-1,000) per year (ADB, 2018). One participant mentioned that "if you compare the results of public and private schools according to results of school certificate. Private schools do better." (INT3). On the other hand, dropout rates are another crucial issue in the secondary level of education. The data indicated from Banbeis (2018) pointed that gross enrolment rate at the secondary level is $60.45 \%$ and completion rate is $62.79 \%$ (Sultana, 2018).

In last decade satellite schools established for children who are homeless or immigrate. In addition to that for the reason of Bangladesh consist of wetlands that hardening to reach rural side of the country BRAC (Building Resources Across Communities) - a non-governmental organization, provide boat school option to serve unprivileged children. This model has positive impact on socio-economic changes (Ahmed et al., 2017). Moreover, some participants mentioned that many poor families who live in extreme poverty tend to enroll their children to Quomi madrasahs for facilities that they provide (INT5, INT4, INT12, INT13, INT14, and INT16). "Despite the fact, Quomi madrasahs' curriculum is not relevant to job market; parents take the advantage of free education. Moreover, until supreme level of Quomi madrasahs, none of the students' has a chance to change school because there is no accreditation (INT 16). As Sommers (2011) stated many rural quomi madrassas are also orphanages, they are seen as an option for families who cannot send their children to school. The aforementioned situation is the basic example of 'reproduction in education' concept (Bourdeu and Passeron, 1990) Children started school in an early age and such a decision would shape rest of his life. After graduation from Quomi madrasah alumni have very limited job opportunities.

\subsection{Knowledge Intensive Economy}

Knowledge plays an essential role in both societies and economies. In fact, they are characterized with a great deal of information with easy access available for citizens and firms, improving educational qualifications, and the significance of knowledge in daily life including work environment (Tunalı and Kiraz, 2017b).

Results indicated that there is a huge confusion in education of Bangladesh in terms of connection of economy and education. As mentioned under the population heading, especially youth population is very high in Bangladesh. In addition to that, unemployment rates are dramatically high too. There is a huge mismatch among the population, job market and education (Gutierrez et al., 2019). Some participant mentioned the importance of vocational schools. Increasing the number of vocational and technical schools can support to be more skillful (INT1, INT2, INT3, and INT5). One participant mentioned that "In the 7th five-year plan vocational education become one important issue. But there is a need for a big investment for training and development of industry to implement this plan."(INT3). On the other hand, a participant mentioned that the mindset of people is another barrier to productivity. "Everybody likes to be a member of the gentlemanly class in Bangladesh society. There is a historical background for the mindset of Bangladeshi people towards the job market" (INT5, female). We can speculate that there is a social stigma against vocational and technical education. Social recognition of vocational education is not positive so, parents usually expecting their children continue to higher education without consideration of academic achievement and ability. Additionally, there is a lack of carrier guidance for technical occupations in Bangladesh and abroad as well. This high demand for higher education is one of the main reasons for the increasing number of private universities (INT1, INT2, INT3, INT5, and INT8). Finally yet importantly, one participant used the analogy of "inferior goods" to explain the situation of madrasah education and vocational education.

Although Bangladesh still have arable lands, global warming is an important threat. Many of the productive farms have left underwater until today. Especially textile industry has a very important contribution but there are not many endeavors to support the service industry like tourism. In addition to that, big chunks of people are going to Malaysia and Middle East (Saudi Arabia, United Arab Emirates, Qatar, etc.) to attain service industry related works like housekeeping, construction or technic. INT4 stated that every year more than one million people are going abroad to work by the support of government. Bangladeshi who are educated in international standards usually prefer to work in England, Europe, and Australia but none of the interviewees stated about brain drain as a problem. One professor from sociology mentioned that "After the Independence War of Bangladesh very well educated Bangladeshi immigrate to different countries because of the instability of the country but nowadays brain drain is not a case" (INT8). Although brain drain is a real problem in the world, participants mentioned that for Bangladeshi this is not a case. The population of youth in Bangladesh is the highest in the world. One can speculate that the engagement of youth working abroad seems considerable. "We cannot only focus on national-level recruitment. There is also a need to be aware of global needs. Recently, World Bank organized a seminar related to "gig economy". This means you need skills to hire. (INT3).

Some participants mentioned that there are so many debates have been going on in related to religious and cultural identities of Bangladeshi but there is not any debate on socio-economic goals. The conflicts between fundamentalist and secular groups in policy causing instability and economic growth are not possible in this kind of 
ecosystem (INT5, INT4). "Policymaking in Bangladesh could be proactive neither in South Asia nor Global area. Policies are more reactive rather than proactive in every sector” (INT5).

\subsection{Skills for the Future of Work}

Knowledge is seen as a requirement for economic development and prosperity, as a result of which education has gained more importance in political agendas. A lot of debate on how successful education systems are in meeting the demands of an economy based on knowledge has been going on OECD (2010). One participant mentioned that in Bangladesh the most important thing is "there is no information about the demand estimation of economy."(INT3). To put a plan in action this information is very crucial.

The fact that economies are getting more integrated and influences strategies employed for national competitiveness, innovation, employment and skills. It can also have an impact on the way attitudes and expertise enhancing international trade and collaboration are shaped. As for education, the global integration of economies may bring about a need and opportunity to develop various new skills. These interconnections crossing borders have shaped agendas, skill estimates and occupations. In the field of education, subjects covered in basic and higher education are directly affected by primary skills to be developed; for instance, giving priority to science and mathematics, or harmonizing creativity with arts to encourage innovation (OECD, 2013; Rahman et al., 2019). Trade and R\&D among nations along with a knowledge-intensive economy have resulted in the 21 st-century skills that must be possessed by the youth. On the other hand, the increase in lifespan and drop in birth rate make lifelong learning necessary for everyone.

According to the interview results, six Participants mentioned about the skills for the future of work (INT1, INT2, INT6, INT7, INT9, and INT10). Participants stated that especially schools which medium of instruction is in English mostly focus on 21 st-century skills and their instructional foci is the global job market. On the other hand, many schools in Bangladesh don't have any awareness in terms of skills for the future of work. "We are giving priority to global citizenship and global work life. However, many Bangladeshi schools are not aware of the importance of 21st-century skills. There is a huge skill mismatch between Bangladeshi schools and work-life" (INT7, Male). In the Vision Statement for 2021 of government, ICT skills considered as the core but in implementation, there are many limitations. School infrastructure and teacher shortage are the main barriers for ICT education (INT2, INT3, INT7, INT9, and INT10).

Some participants mentioned that the nation of Bengal is oppressed for many centuries due to colonization (INT3, INT4, and INT7). In his distinguished book "Pedagogy of the Oppressed" Paul Freire discussed the mindset of oppressed people and its reflection on education in the case of Brazil. The main problem of his case is: how to create an education system with oppressed people, for oppressed people, that will help them become more free. In Bangladesh case, Bangladeshi tend to protect their native language (Bangla). Maybe most of the people are not aware of Bangla but nearly 200 million people are talking this language as mother tongue. Fear of assimilation concerning social and cultural issues was also a barrier to consider global needs in schools. However, in the last decade the number of schools that medium of instruction in English has rapidly increased. There are also some public primary schools, which implement the English curriculum developed by National Curriculum and Textbook Board (NCTB) of Bangladesh. This English curriculum is the same as the curriculum in Bangla (INT2, INT6, INT7, INT9, INT10, INT12, and INT13). This is very hard to keep a balance between global and local needs at the same time even for developed countries but learning a foreign language is a very important competency in today's world.

\section{Conclusion}

Economic development and poverty reduction, together with human resources development, has been key strategic priorities of the Government of Bangladesh's medium-term, national development plans (Third Plan [1985-1990]; Fifth Plan [1997-2002]; Seventh Plan [2016-2020]). The plan identifies improving education quality and emphasizes: (1) curriculum reform; (2) elimination of discrepancies among schools with respect to school infrastructure, facilities, number of teachers, and training opportunities; (3) reduction in dropouts; (4) provision of special interventions for marginalized indigenous children, physically retarded, street children, and other ultra-deprived children; and (5) improvement of the school milieu (ADB, 2018).

This was consistent with the Government of Bangladesh's initiative on Education for All (EFA) started in 1992, and adopted as a national action plan in 2003. Along with economic growth and governance, human development is one of the three pillars of the Government of Bangladesh's current, long-term National Poverty Reduction Strategy (NPRS; 2006-2015). The National Poverty Reduction Strategy I, based on Millennium Development Goals (MDGs), as it aims to reduce poverty too (ADB, 2018). In the light of afore mentioned we can say that various initiations of the state is based on internationally recognized strategies. On the other hand, in implication of strategies is not effective as expected. According to the ADB (2018) Report the decline in national student assessments results is related to the expansion of school samples between 2011-2015. Schools have wide variety in many factors: teacher profiles (qualification and training), student's background (socioeconomic conditions), and physical school facilities (learning environment) (ADB, 2018). This results are proof how child poverty influential on academic achievement.

Teacher shortage and teacher quality are some of the other barrier for improving skills in students. The Ministry of Education in Bangladesh declared that \%40 percent of public primary school teachers haven't got university degree. They started to teach after graduate from secondary or higher secondary level (Ministry of Primary and Mass Education of Government of Bangladesh, 2015). In addition to that, less than $50 \%$ of the primary teachers are proficient in teaching. On average, $27 \%$ of the positions of head teacher (primary school principal, who often also teaches) and 7\% of assistant teacher positions were vacant throughout 2016 (ADB, 2018).

In sum, considering education and economy go hand in hand there is a need for a macro plan. Because today world is considering digitalization and artificial intelligence in business and if this skill mismatch will continue to grow in the future uneducated and unskilled masses will be more problematic than ever. Educational institutions and policymakers must be aware of the future of the job market and work to improve the productivity of the 
economy. As a result, robust and sustainable educational policies are highly important to ensure quality education for all Bangladeshi. Bangladesh is a developing country acceleration in the economy is remarkable and great emphasis on education can help to handle some of the causes of inequality by equipping poor individuals with necessary cognitive and social skills in the modern world.

\section{References}

ADB, 2008. Education sector in Bangladesh: What worked well and why under the sector-Wide Approach? Reference Number: SAP: BAN 2008-82 Sector Assistance Program Evaluation Report.

Ahmad, Q.K., 2007. Education watch 2006: Financing primary and secondary education in Bangladesh. Bangladesh: Campaign for Popular Education (CAMPE).

Ahmed, J.U., N. Ashikuzzaman and A.S.M. Mahmud, 2017. Social innovation in education: BRAC boat schools in Bangladesh. Journal of Global Entrepreneurship Research, 1(7): 1-14.Available at: https://doi.org/10.1186/s40497-017-0077-z.

Ali, A.K.M.Y., 2007. Arabic and persian studies under Bengal Sultanate: An sppraisal. The lecture has been delivered under the Professor Muhammad Nurul Karim Trust Fund Lecture programme. Available from http://www.bmri.org.uk [Accessed 08.12.2018].

American Educational Research Association (AERA), 2011. Code of ethics. 40(3): 145-156.

Amin, M.A. and J. Greenwood, 2018. The examination system in Bangladesh and its impact: On curriculum, students, teachers and society. Language Testing in Asia, 8(1): 1-18.Available at: https://doi.org/10.1186/s40468-018-0060-9.

Asia Development Bank (ADB), 2018. Supporting fourth primary education development program. Summary Sector Assessment: Education. Available from https://www.adb.org/sites/default/files/linked-documents/50192-002-ssa.pdf [Accessed 13.12.2018].

Banbeis, 2018. Bangladesh educational statistics 2017. Available from http://data.banbeis.gov.bd/ [Accessed 09.12.2018].

Bangladesh Bureau of Educational Information and Statistics, B., 2018. Bangladesh educational statistics 2017. Available from http://data.banbeis.gov.bd/ [Accessed 09.12.2018].

Bogdan, R. and S.K. Biklen, 1992. Qualitative research for education. USA: Allyn and Bacon.

Bourdeu, P. and J.-C. Passeron, 1990. Reproduction in education, society and culture. Sage Publications.

Chowdhury, R. and A.H. Kabir, 2014. Language wars: English education policy and practice in Bangladesh. Multilingual Education, 4(1): 116.Available at: https://doi.org/10.1186/s13616-014-0021-2.

Global Education Monitoring Report, G., 2017. Accountability in education: Meeting our commitments. UNESCO Publishing.

Guba, E.G., 1981. Criteria for assessing the trustworthiness of naturalistic inquiries. Educational Communication and Technology Journal, 29: $75-91$.

Gutierrez, I.A., K.B. Kumar, M. Mahmud, F. Munshi and S. Nataraj, 2019. Transitions between informal and formal employment: Results from a worker survey in Bangladesh. IZA Journal of Development and Migration, 9(1): 1-27.Available at: https://doi.org/10.1186/s40176-019-0141-2.

Hossain and B. Zeitlyn, 2010. Poverty and equity: Access to education in Bangladesh, CREATE pathways to access, research monograph No 51. Brighton: University of Sussex.

Mateu, M., C. Cobo and J. Moravec, 2018. Plan Ceibal 2020: Future scenarios for technology and education-the case of the Uruguayan public education system. European Journal of Futures Research, 6(1): 1-12.Available at: https://doi.org/10.1186/s40309-018O134-Z.

Ministry of Primary and Mass Education of Government of Bangladesh, 2015. Annual primary school census. Available from http://dpe.portal.gov.bd/sites/default/files/files/dpe.portal.gov.bd/publications/f2501e16_4f57_467b_8c67_48a5855f88fe/Final \%20Draft\%20APSC2015.pdf [Accessed 10.10.2018].

Nath, S.R., 2007. Remunerated supplementary tutoring in out-of-school study in rural Bangladesh. BRAC Research Report, BRAC Research \& Evaluation Division. Available from http://www.bracresearch.org/reports/remunerated_supplementary.pdf [Accessed 10 July $2011]$.

OECD, 2010. Trends shaping education. OECD schooling for tomorrow series. Paris: OECD.

OECD, 2011. Society at a glance: Asia/ Pacific 2011. Paris: OECD.

OECD, 2013. Trends shaping education. OECD schooling for tomorrow series. Paris: OECD.

OECD, 2016. Trends shaping education. OECD schooling for tomorrow series. Paris: OECD.

Organisation for Economic Co-operation and Development, R., 2006. Starterpack: The futures thinking in action. OECD schooling for tomorrow Series. Paris: OECD.

Pridmore, P., 2007. Impact of health on education access and achievement: A cross national review of the research evidence, CREATE Pathways to Access, Research Monograph No 2, Institute of Education, University of London.

Rahman, M.M., M.S. Islam, A. Karim, T.A. Chowdhury, M.M. Rahman, P.M.I. Seraj and M.K.M. Singh, 2019. English language teaching in Bangladesh today: Issues, outcomes and implications. Language Testing in Asia, 9(1): 1-14.

Shenton, A.K., 2004. Strategies for ensuring trustworthiness in qualitative research projects. Education for Information, 22(2): 6375.Available at: https://doi.org/10.3233/efi-2004-22201.

Sommers, C., 2011. Primary education in rural Bangladesh: Decrees of access, choice, and participation of the poorest.

Sultana, N., 2018. Test review of the English public examination at the secondary level in Bangladesh. Language Testing in Asia, 8(1): 19.Available at: https://doi.org/10.1 186/s40468-018-0068-1.

Teach for Bangladesh, 2016. Fellow survey data. Available from https://www.teachforbangladesh.org/assets/annual-report-2016.pdf [Accessed 05.11.2018].

Tunal, S., 2019. Exploring the schools of the future - scenarios. (discovering the schools of the future-scenarios). TASAM Publishing.

Tunal, S. and E. Kiraz, 2017a. Using research methods on future in educational research. Journal of Education, 31(2): 41-54.

Tunal, S. and E. Kiraz, 2017b. The social and demographic trends that shaping education in Turkey. Researchs on Science and Art in 21 st Century Turkey. Gece Press Publishing.

World Bank, 2011b. Project appraisal document on a proposed credit of SDR 187.5 Million (US\$300 Million Equivalent) to the people's republic of Bangladesh for a Third Primary Education Development Programme, World Bank Report No: 6032 1-B.

World Population Review, 2018. Available from http://worldpopulationreview.com/world-cities/dhaka-population/ [Accessed 25.10.2018]. 